\title{
The SLEEP GOAL as a success criteria in obstructive sleep apnea therapy
}

\author{
Kenny P. Pang ${ }^{1} \cdot$ Brian W. Rotenberg ${ }^{2}$
}

Received: 19 November 2015 / Accepted: 18 February 2016/Published online: 22 February 2016

(C) Springer-Verlag Berlin Heidelberg 2016

\section{Dear Editor,}

Obstructive sleep apnea (OSA) is a common illness affecting $9 \%$ of middle age men in North America and $3 \%$ of women [1]. It is a debilitating disorder that affects the patients primarily at night, but manifests mainly in the daytime. The snoring at night affects not only the bedpartner's sleep quality, but may also cause break down in the marriage and relationship. Tiredness, poor concentration and irritability disrupt the snorer's quality of life, work and productivity. This seemingly innocuous five-letter word, sleep, affects the patient's mood, temper, emotional state, relationships, work performance, promotions, monthly salary and his entire being/life.

Successfully and holistically treating a patient with OSA would imply reversing debilitating symptoms faced by the patient, including the metabolic and oxidative stress that accompanies the disease load and disease burden. Moreover, recent evidence has shown significant discordance between the levels of AHI used to denote outcomes of therapy and real world clinical outcomes such as QOL, patient perception of disease, cardiovascular measures, disease burden and/or survival [1-5]. There is a mountain of evidence showing how the AHI can vary from night to night, vary from laboratory to laboratory, from various nasal thermistor to pressure transducers, and AHI can vary based on the different definitions of hypopnea used in different laboratories and software [6-14]. The

Kenny P. Pang

drkpang@gmail.com

1 Asia Sleep Centre, Paragon Medical Centre, Singapore 238859, Singapore

2 Department of Otolaryngology, Head and Neck Surgery, Western University, London, Canada contemporary reliance on AHI as generally the only outcome measure assessed in research programs is not in line with many other aspects of medicine that are becoming patient centered as opposed to test centered [6-14].

According to the surgical literature on OSA treatment, Sher's success criteria of $50 \%$ reduction in AHI and an AHI less than 20 tend to be the benchmark for success [15]. However, this archaic concept was based entirely on an arbitrary AHI number that did not stratify the patients by likelihood of surgical success. These oft-quoted criteria should be abandoned as being both insufficient and out of date. Hobson et al. recently showed in a creative study that differences even in the definition of AHI severity cut-off can greatly influence reported efficacy of surgery in patients with OSA [16]. For example, a patient with preoperative AHI of 95 who has a post-operative PSG showing an AHI of 21, would likely experience significant symptomatic clinical improvement with a huge decrease in disease burden (in terms of obesity, hypertension, cardiovascular effects) even though they are not, by definition, considered a successful surgical outcome by the numerical AHI criteria, whereas a patient with a pre-operative AHI of 35 , reduced post-operatively to under 14 , is considered a successful AHI outcome even though the likelihood of clinical cardiovascular, disease burden and/or QOL impact may be minimal. It is essential that OSA treatment has clinical significance rather than satisfy some numerical criteria.

When considering OSA treatment clinicians need to consider the impact that OSA has on the patho-physiological response, including the cardio-vascular, neurological, psychological, metabolic and emotional aspects of the disease burden/load. There have been many research articles demonstrating strong correlations between OSA and blood pressure changes, OSA and body mass index (BMI), 
OSA and Epworth sleepiness scale (ESS), and OSA with quality of life (QOL) parameters [17-25]. Any treatment intervention given to the OSA patient, surgical or otherwise, should address these strong correlations as they reflect the disease burden/load in the OSA patient, not just a numerical AHI criteria based on only one sleep parameter, but the entire constellation of parameters that affect the patient.

We propose the acronym SLEEP GOAL, as a more comprehensive set of success parameters:

S Snoring VAS-improvement in VAS by five points

L Latency of sleep onset (PSG or MLST) normalization of sleep latency (if it was abnormal pretreatment), and/or improvement/normalization of the MSLT

E Epworth sleepiness scale-normalization to less than 10 (if it was abnormal pre-treatment), or a reduction by five points

E Execution time-improvement by more than $50 \%$, using performance vigilance testing

$\mathrm{P}$ Pressure (SBP) - (a) reduction in mean blood pressure by $7 \mathrm{mmHg}$, or (b) single reduction in either SBP or DBP by $10 \mathrm{mmHg}$ or (c) $5 \mathrm{mmHg}$ reduction in both

G Gross weight/BMI-loss of $>10 \%$ gross weight, and/ or reduction BMI from one category to another (by four points)

$\mathrm{O}$ Oxygenation-improvement of duration $(\mathrm{min})$ of $\mathrm{O}_{2}$ $<90 \%$ by at least half

A AHI via sleep study-reduction by $50 \%$ and AHI $<20$

L Life score (PSQI) - improvement in a relevant OSA related QOL score (i.e. PSQI or SF36 or FOSQ)

It would be crucial to understand that treatment of an OSA patient would not only be confined to upper airway surgery, bariatric surgery, CPAP therapy and/or oral appliance usage, treatment intervention may include, for example, a simple strict weight loss program; by drastically decreasing the BMI of the patient, the patient's metabolic stress decreases, quality of life improves, the para-pharyngeal and tongue fat would decrease, hence, the upper airway size might improve, providing better oxygen levels at night, lowered blood pressure and less cardiovascular risk/complications in the long term.

We recognize that implementing such criteria would complicate rather than simplify the management of OSA, but this would stand in contrast to the gross over simplification of the disease management that currently occurs by the use of AHI alone. It would be plausible to state that the paradigm of OSA treatment outcomes needs to be better thought through, redefined and shifted to a more holistic, comprehensive and realistic patient-centered parameters. We introduce these suggested parameters as a jump-start to open the discussion, and we are currently validating our proposed SLEEP GOAL success criteria by collecting data from a prospective multi-center clinical trial that is ongoing.

\section{Compliance with ethical standards}

Conflict of interest The authors declare that there is no conflict of interest.

\section{References}

1. Moyer CA, Sonnad SS, Garetz SL, Helman JI, Chervin RD (2001) Quality of life in obstructive sleep apnea: a systematic review of the literature. Sleep Med 2(6):477-491

2. Wright J, Johns R, Watt I, Melville A, Sheldon T (1997) Health effects of obstructive sleep apnoea and the effectiveness of continuous positive airways pressure: a systematic review of the research evidence. BMJ 314(7084):851-860

3. Thong JF, Pang KP (2008) Clinical parameters in obstructive sleep apnea: are there any correlations? J Otolaryngol Head Neck Surg 37(6):894-900

4. Piccirillo JF (2009) outcomes research and obstructive sleep apnea. Laryngoscope 110(S94):16-20

5. Tam S, Woodson BT, Rotenberg BW (2013) Outcome measurements in obstructive sleep apnea: beyond the apnea-hypopnea index. Laryngoscope. doi:10.1002/lary.24275

6. Chediak AD, Acevedo-Crespo JC, Seiden DJ, Kim HH, Kiel MH (1996) Nightly variability in the indices of sleep-disordered breathing in men being evaluated for impotence with consecutive night polysomnograms. Sleep 19:589-592

7. Le Bon O, Hoffmann G, Tecco J, Staner L, Noseda A, Pelc I, Linkowski P (2000) Mild to moderate sleep respiratory events: one negative night may not be enough. Chest 118:353-359

8. Dean RJ, Chaudhary BA (1992) Negative polysomnogram in patients with obstructive sleep apnea syndrome. Chest 101:105-108

9. Pittsley M, Gehrman P, Cohen-Zion M, Stepnowsky C, Marler M, Ancoli-Israel S (2005) Comparing night-to-night variability of sleep measures in elderly African Americans and Whites. Behav Sleep Med 3(2):63-72

10. Levendowski D, Zack N, Rao S, Wong K, Gendreau M, Kranzler J, Zavora T, Westbrook PR (2009) Assessment of the test-retest reliability of laboratory polysomnography. Sleep Breath 13(2):163-167

11. Stepnowsky CJ Jr, Orr WC, Davidson TM (2004) Nightly variability of sleep-disordered breathing measured over three nights. Otolaryngol Head Neck Surg 131(6):837-843

12. Levendowski D, Steward D, Woodson BT, Olmstead R, Popovic D, Westbrook P (2009) The impact of obstructive sleep apnea variability measured in-lab versus in-home on sample size calculations. Int Arch Med 2(1):2

13. Westbrook P, Levendowski D, Cvetinovic M, Zavora T, Velimirovic V, Henninger D, Nicholson D (2005) Description and validation of the apnea risk evaluation system: a novel method to diagnose sleep apnea-hypopnea in the home. Chest 128:2166-2175

14. Ayappa I, Norman RG, Seelall V, Rapoport DM (2008) Validation of a self-applied unattended monitor for sleep disordered breathing. J Clin Sleep Med 4:26-37

15. Sher AE, Schechtman KB, Piccirillo JF (1996) The efficacy of surgical modifications of the upper airway in adults with obstructive sleep apnea syndrome. Sleep 19(2):156-177

16. Hobson JC, Robinson S, Antic NA et al (2012) What is "success" following surgery for obstructive sleep apnea? The effect of 
different polysomnographic scoring systems. Laryngoscope 122(8):1878-1881

17. Ranqemark C, Hedner JA, Carlson JT et al (1995) Platelet function and fibrolytic activity in hypertensive and normotensive sleep apnea patients. Sleep 18:188-194

18. Dean RT, Wilcox I (1996) Possible atherogenic effects of hypoxia during OSA. Sleep 16:S15-S22

19. Schulz R, Mahmoudi S, Hattar K et al (2000) Enhanced release of superoxide from polymophonuclear neutrophils in OSA. Am J Respir Crit Care Med 162:566-570

20. Mooe T, Franklin KA, Holmstrom K et al (2001) Sleep disordered breathing and coronary artery disease: long term prognosis. Am J Resp Crit Care Med 164:1910-1913
21. Peker Y, Hedner J, Kraiczi H et al (2000) Respiratory disturbance index: an independent predictor of mortality in coronary artery disease. Am J Resp Crit Care Med 162:81-86

22. Bradley TD (1992) Right and left ventricular functional impairment and sleep apnea. Clin Chest Med 13:459-479

23. Partinen M, Palomaki H (1985) Snoring and cerebral infarction. Lancet 2:1325-1326

24. Kos Kenvuo M, Partinen M, Sarnas et al (1985) Snoring as a risk factor for hypertension and angina pectoralis. Lancet 1:893-895

25. Hoffstein V (1996) Snoring. Chest 109:201-222 